\title{
Effects of fermented ginseng on memory impairment and $\beta$-amyloid reduction in Alzheimer's disease experimental models
}

\author{
Joonki Kim ${ }^{1}$, Sung Hun Kim ${ }^{1}$, Deuk-Sik Lee ${ }^{2,3}$, Dong-Jin Lee ${ }^{3}$, Soo-Hyun Kim ${ }^{3}$, Sungkwon Chung ${ }^{4}$, \\ and Hyun Ok Yang ${ }^{1^{*}}$ \\ ${ }^{1}$ Natural Medicine Center, Korea Institute of Science and Technology, Gangneung 210-340, Korea \\ ${ }^{2}$ Division of Hotel Culinary and Food Service, Hanzhong University, Donghae 240-713, Korea \\ ${ }^{3}$ Institute of Life Science, Well-Being LS Co. Ltd., Gangnueng 210-340, Korea \\ ${ }^{4}$ Department of Physiology, Samsung Biomedical Research Institute, School of Medicine, Sungkyunkwan University, Suwon, \\ Korea
}

This study examined the effect of fermented ginseng $(\mathrm{FG})$ on memory impairment and $\beta$-amyloid $(\mathrm{A} \beta)$ reduction in models of Alzheimer's disease (AD) in vitro and in vivo. FG extract was prepared by steaming and fermenting ginseng. In vitro assessment measured soluble A $\beta 42$ levels in HeLa cells, which stably express the Swedish mutant form of amyloid precursor protein. After 8 $\mathrm{h}$ incubation with the FG extract, the level of soluble A $\beta 42$ was reduced. For behavioral assessments, the passive avoidance test was used for the scopolamine-injected ICR mouse model, and the Morris water maze was used for a transgenic (TG) mouse model, which exhibits impaired memory function and increased A $\beta 42$ level in the brain. FG extract was treated for 2 wk or 4 mo on ICR and TG mice, respectively. FG extract treatment resulted in a significant recovery of memory function in both animal models. Brain soluble A $\beta 42$ levels measured from the cerebral cortex of TG mice were significantly reduced by the FG extract treatment. These findings suggest that FG extract can protect the brain from increased levels of $A \beta 42$ protein, which results in enhanced behavioral memory function, thus, suggesting that FG extract may be an effective preventive or treatment for $\mathrm{AD}$.

Keywords: Panax ginseng, Fermented ginseng, Alzheimer's disease, Beta-amyloid, Animal model

\section{INTRODUCTION}

Alzheimer's disease (AD) is a progressive neurodegenerative disorder diagnosed clinically by loss of cognition and memory, and pathologically by the increase of $\beta$-amyloid $(\mathrm{A} \beta)$ and deposition of $\mathrm{A} \beta$ plaques in the brain $[1,2]$. Increased proteolytic degradation of $\beta$-amyloid precursor protein (APP), the precursor for $A \beta$, is considered the primary cause of the disease process [3]. Overpopulated $A \beta$ peptides tend to oligomerize, which leads to polymerization, conformational change, fibrillation, and deposition of fibrillar $\mathrm{A} \beta$ plaques within the brain

(c) This is an Open Access article distributed under the terms of the Creative Commons Attribution Non-Commercial License (http://creativecommons.org/licenses/by-nc/3.0/) which permits unrestricted non-commercial use, distribution, and reproduction in any medium, provided the original work is properly cited. parenchyma [4]. Currently, many attempts have been made to identify or develop agents capable of controlling A $\beta$-related mechanisms of AD [5]. However, there still remains no cure for $\mathrm{AD}$, and the majority of currently approved treatments offer only symptomatic relief at best. This has triggered a thorough investigation of herbal therapeutics that has long been utilized in traditional medicines to treat aging and memory loss.

For thousands of years, ginseng, commonly known as Panax ginseng Meyer, has been used in traditional medi-

Received 03 Aug. 2012, Revised 27 Sep. 2012, Accepted 02 Oct. 2012

\footnotetext{
*Corresponding author

E-mail: hoyang@kist.re.kr

Tel: +82-33-650-3501, Fax: +82-33-650-3529
} 
cine as a general body tonic [6]. Ginseng has also been used regularly for a multitude of applications with associative functions. An example is the use of ginseng as a central nervous system stimulant to improve cognitive function, including marked effects on memory and learning as well as ameliorating confusion and forgetfulness often encountered with aging [7]. Based on previous research, ginsenosides are the main molecular components that are effective in the treatment of cognitive impairments [8], including the amelioration of $\mathrm{A} \beta$ plaques [910]. However, various other components of $P$. ginseng, including polysaccharides, peptides, polyacetylenic alcohols, and fatty acids, have also been identified as biologically active [11].

In an effort to determine a safer and more effective agent with increased amounts of various ginsenosides, fermented ginseng (FG) was developed. FG contains high levels of Rg3, Rg5, and Rk1 that have been bioconverted from Re, Rg1, and Rb1. Recently, FG was found to have hypolipidemic and hypoglycemic effects $[12,13]$ as well as anti-cancer [14], anti-inflammatory $[15,16]$, and therapeutic effects on allergic rhinitis in clinical patients [17]. However, there are no reports on the effect of FG on cognition impairment or AD. Therefore, in the present study, the effect of FG on chemicallyinduced amnesia mouse model and enhancement of $A \beta$ related symptoms in $\mathrm{AD}$ transgenic (TG) mice were investigated, as well as in vitro investigation of mutated HeLa cells in an effort to reduce $A \beta$ levels.

\section{MATERIALS AND METHODS}

\section{Preparation and analysis of fermented ginseng ex- tract}

Six-year-old root of $P$. ginseng Meyer was purchased from a traditional medicine market in Hongcheon, Korea. Well-being LS Co. Ltd. (Gangneung, Korea) manufactured the FG extract through steaming, drying, and fermentation processes. Briefly, the ginseng root was steamed for $15 \mathrm{~min}$ at $121^{\circ} \mathrm{C}$ and dried until the water content was below $12 \%$. Next, $10 \mathrm{~g}$ of the processed root were extracted with $200 \mathrm{~mL}$ of distilled water for $2 \mathrm{~h}$ and inoculated with $3 \%$ Lactobacillus fermentum $\left(1 \times 10^{8}\right.$ $\mathrm{cfu} / \mathrm{g}$ ) for $16 \mathrm{~h}$ of fermentation at $42^{\circ} \mathrm{C}, 80 \mathrm{rpm}$. The FG extract was then sterilized with an autoclave at $121^{\circ} \mathrm{C}$ for $15 \mathrm{~min}$. For comparison, dried ginseng (DG) extract was also prepared by a $22 \mathrm{~h}$ water extraction with $10 \mathrm{~g}$ of dried ginseng root (water content less than 12\%) and 200 $\mathrm{mL}$ of distilled water. FG and DG extracts were freezedried and analyzed for their active components by HPLC using YL9100 HPLC system (Younglin, Anyang, Korea) that was equipped with a YL9160 PDA detector and an ELSD ZAM 3000 detector (Schambeck SFD GmbH, Bad Honnef, Germany).

\section{In vitro soluble $\boldsymbol{\beta}$-amyloid $\mathbf{4 2}$ detection}

A HeLa cell line stably expressing the Swedish mutant form of APP (APPswe) was maintained in Dulbecco's modified Eagle medium supplemented with $10 \%$ heat-inactivated fetal bovine serum, as previously described [18]. Briefly, the cells were plated at $70 \%$ to $80 \%$ confluence in $60 \mathrm{~mm}$ dishes. The cells were pre-incubated with FG or DG extract 200 and $400 \mu \mathrm{g} / \mathrm{mL}$ concentrations for $8 \mathrm{~h}$. Then, media was collected, and cell debris was removed by centrifugation at $12,000 \mathrm{rpm}$ for $5 \mathrm{~min}$. The levels of A $\beta 42$ in conditioned media were determined using sandwich ELISA (human A $\beta 42$, \#KHB3482; BioSource International Inc., Camarillo, CA, USA) according to the manufacturer's protocol.

\section{Animals}

For the scopolamine-induced amnesia model, 7- weekold male ICR mice were obtained from Orient Bio Inc. (Seongnam, Korea). Male APP/PS1 double-TG mice (strain name, B6C3-Tg(APPswe/PSEN1dE9)85Dbo/J; stock number 004462) used in this study were obtained from Jackson Laboratory (Bar Harbor, ME, USA) at the age of 4 months old. TG mice expressed a chimeric mouse/human APP containing the K595N/M596L Swedish mutations and a mutant human presenilin-1 carrying the exon 9-deleted variant under the control of mouse prion promoter elements, which directs the transgene expression predominantly to central nervous system neurons. All animals were housed in solid bottom cages with pellet food and water available ad libitum. The mice were also maintained on a 12/12 h light-dark cycle in a temperature and humidity-controlled room $\left(22^{\circ} \mathrm{C}, 50 \%\right)$. The animal protocols used in this study were in accordance with the Korea Institute of Science and Technology Animal Care Committee guidelines.

\section{Step-through passive avoidance test}

A two-compartment step-through passive avoidance apparatus (Jeung Do Bio \& Plant Co., Seoul, Korea) was used for the test. The apparatus was divided into bright and dark compartments $\left(10 \times 12 \times 15 \mathrm{~cm}^{3}\right.$ each $)$ by a wall with a guillotine door. The bright compartment was illuminated by a fluorescent light $(8 \mathrm{~W})$. Eight weeks old ICR mice were randomly grouped and administered 400 or $800 \mathrm{mg} / \mathrm{kg} / 10 \mathrm{~mL}$ oral doses of FG extract. The 
other groups were administered saline. After 2 wk of FG extract pre-treatment, the mice were injected with $1 \mathrm{mg} /$ $\mathrm{kg}$ of scopolamine or vehicle by intra peritoneal injection 45 min prior to the training session. During the training session, the mice were placed in the bright compartment and allowed to explore for $30 \mathrm{~s}$, at which point the guillotine door was raised to allow the mice to enter the dark compartment. When the mice entered the dark compartment, the guillotine door was closed, and an electrical foot shock $(0.3 \mathrm{~mA})$ was delivered for $3 \mathrm{~s}$, and the mice were then placed back into their cages. After $24 \mathrm{~h}$, a test session was performed. During the test session, the mice were placed in the bright compartment and allowed to explore for $30 \mathrm{~s}$, and then, the guillotine door was raised. The latency to enter the dark compartment was recorded for up to $300 \mathrm{~s}$.

\section{Morris water maze test}

Starting at the age of 7 months old, TG mice were randomly grouped and administered the FG extract in doses of 400 or $800 \mathrm{mg} / \mathrm{kg} / 10 \mathrm{~mL}$ for $4 \mathrm{mo}$. The other groups were administered saline during the administration period. The Morris water maze (MWM) consists of a circular pool (120 cm in diameter, and $60 \mathrm{~cm}$ deep) filled with water at $24^{\circ} \mathrm{C}$ to $26^{\circ} \mathrm{C}$ to a depth of $40 \mathrm{~cm}$ and made opaque (white in color) with water soluble non-toxic paint. A non-visible escape platform, $8 \mathrm{~cm}$ in diameter, was submerged approximately $1 \mathrm{~cm}$ below the water's surface in the center of the designated target quadrant. The two phases of the MWM tests, acquisition and retention, were conducted for 7 consecutive days. During the 6 consecutive days of the acquisition phase, each TG mouse was run for total of 3 trials per day, with a $2 \mathrm{~h}$ inter-trial interval. The mice were given a maximum of 90 $\mathrm{s}$ to find the platform and remain seated for at least $5 \mathrm{~s}$. If the mouse was unable to find the platform within the 90 $\mathrm{s}$ time frame, it was placed directly on the platform for 5 $\mathrm{s}$ and then returned to its cage. For each trial, the mouse was placed under one of the 4 visual cues in a random order. During the acquisition phase, escape latency, the amount of time (in seconds) it took the mouse to find the hidden platform, was measured. For those mice that did not find the hidden platform in the allotted time, a score of $90 \mathrm{~s}$ was given. The retention phase of the MWM occurred on the day immediately following the last day of the acquisition phase. During the retention phase, the platform was removed, and the mice were given $120 \mathrm{~s}$ to explore the pool, and the duration of time spent in the target quadrant, which had contained the escape platform during the acquisition phase, was measured. After the test, the mice were removed from the pool and returned to their cages.

\section{In vivo soluble $\boldsymbol{\beta}$-amyloid $\mathbf{4 2}$ detection}

For in vivo detection of brain soluble $\mathrm{A} \beta 42$, the $\mathrm{TG}$ mice that had undergone behavioral tests were anesthetized and decapitated, and the cerebral cortex was dissected from the exposed brains. Brain samples were stored at $-80^{\circ} \mathrm{C}$ until use. The brain samples $(100 \mathrm{mg})$ were homogenized in Tris-buffered saline solution (20 $\mathrm{mM}$ Tris, $137 \mathrm{mM} \mathrm{NaCl}, \mathrm{pH}$ 7.4) containing a complete protease inhibitors tablet (catalog no. P8340; Sigma, St. Louis, MO, USA). The extraction ratio (brain tissue:Trisbuffered saline) was $1: 5$ or $1: 10(\mathrm{w} / \mathrm{v})$. The tissue homogenates were centrifuged at $100,000 \mathrm{~g}$ for $1 \mathrm{~h}$ at $4^{\circ} \mathrm{C}$. Soluble A $\beta 42$ levels in the resulting supernatants were determined using the same sandwich ELISA kit used for the in vitro detection.

\section{Statistical analysis}

All results are presented as the mean \pm SEM. The overall significance of experimental results was examined by Levene's test for variance homogeneity then one-way analysis of variance and the two-tail Dunnet's $t$-test. Differences between the groups were considered significant at $p<0.05$ with the appropriate Bonferroni correction for multiple comparisons.

\section{RESULTS}

\section{Analysis of fermented ginseng and dried ginseng extracts}

According to Fig. 1, $1 \mathrm{~g}$ of DG extract contained undetectable amount of Rg3, Rg5, and Rk1 (Fig. 1A). However, these ginsenosides, Rg3, Rg5, and Rk1, were significantly increased in $1 \mathrm{~g}$ of FG extract to $11.9 \mathrm{mg}, 7.9$ $\mathrm{mg}$, and $6.1 \mathrm{mg}$, respectively (Fig. 1B). In contrast, DG extract contained higher amounts of Re and Rg1 (31.4 $\mathrm{mg}$ ) and $\mathrm{Rb} 1(40.6 \mathrm{mg}$ ) compared with the FG extract containing $4.0 \mathrm{mg}$ and $5.7 \mathrm{mg}$, respectively.

\section{Level of $\beta$-amyloid 42 in fermented ginseng and dried ginseng extract-treated HeLa cell line}

APPswe-mutant HeLa cells exhibited a significantly increased level of $A \beta 42$. DG extract treatment showed no significant effect on the level of $A \beta 42$ expression. However, FG extract 200 or $400 \mu \mathrm{g} / \mathrm{mL}$ treatment resulted in a significant reduction of $A \beta 42$ level to $70.2 \pm 2.7 \%$ and $72.6 \pm 3.0 \%$ compared with the control group, respectively (Fig. 2). 

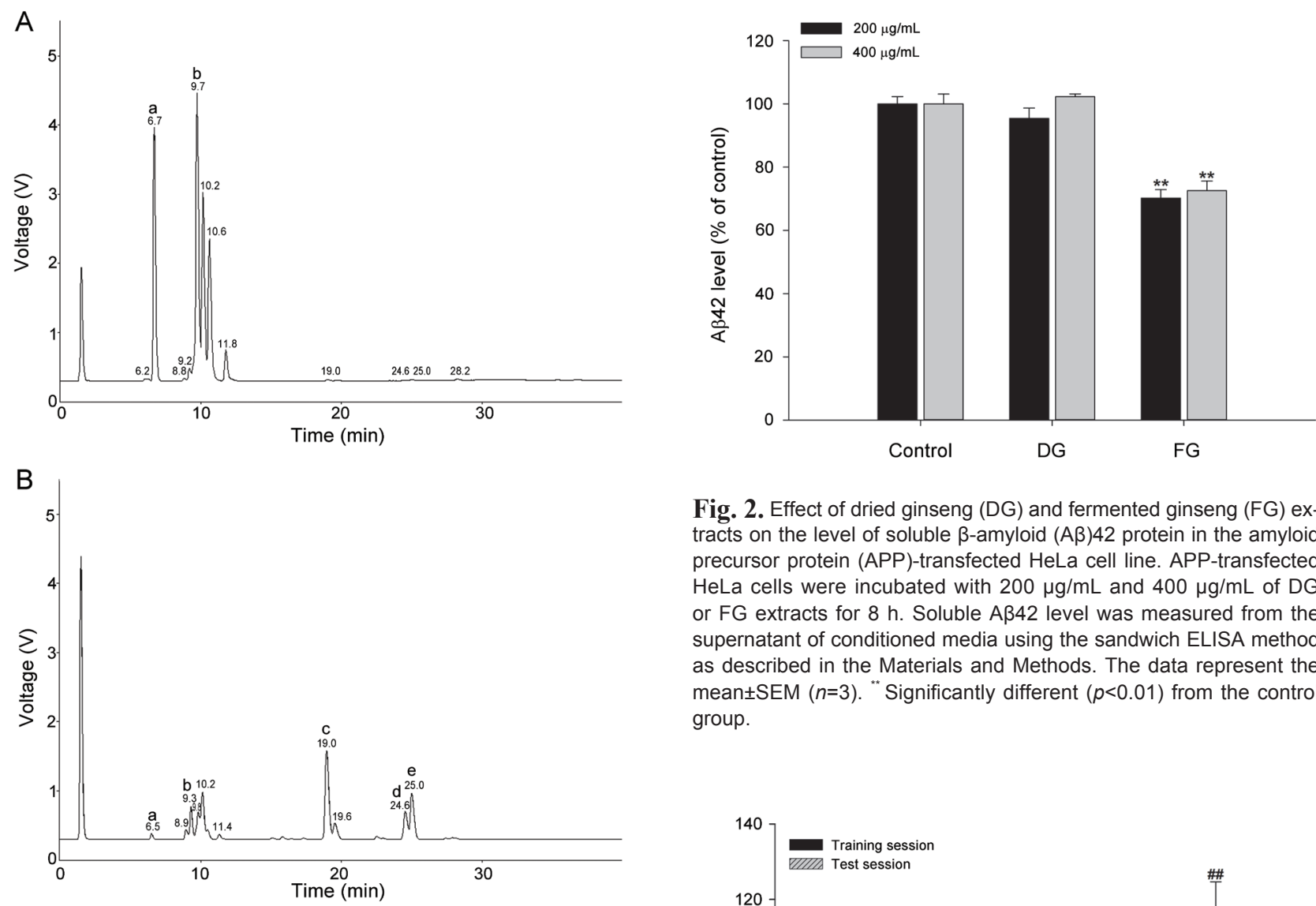

Fig. 1. HPLC analysis of ginsenoside contents in dried ginseng (A) and fermented ginseng (B) extracts. HPLC analysis for ginsenosides was conducted using YL9100 HPLC system, equipped with a YL9160 PDA detector and a ELSD ZAM 3000 detector. Designations of $a, b, c, d$, and e indicate Re+Rg1, Rb1, Rg3, Rk1, and Rg5, respectively.

\section{Effect of fermented ginseng extract on perfor-} mance of the step-through passive avoidance test

ICR mice with scopolamine-induced amnesia were subjected to training with an electrical foot shock session followed by a test session to measure their passive avoidance behavior. As shown in Fig. 3, latency to enter the dark compartment during the training session was not significantly different between the experimental groups. In contrast, during the test session, which was $24 \mathrm{~h}$ after the electric foot shock, the latency to re-enter the dark compartment significantly decreased in the scopolamineinduced amnesia mouse group (16.11 $\pm 3.87 \mathrm{~s})$ compared with the control group (58.25 $\pm 21.28 \mathrm{~s})$. The FG extract treatment $(800 \mathrm{mg} / \mathrm{kg})$ significantly ameliorated the effect of scopolamine and increased the re-entry time to $94.62 \pm 30.01 \mathrm{~s}$.

Fig. 2. Effect of dried ginseng (DG) and fermented ginseng (FG) extracts on the level of soluble $\beta$-amyloid $(A \beta) 42$ protein in the amyloid precursor protein (APP)-transfected HeLa cell line. APP-transfected HeLa cells were incubated with $200 \mu \mathrm{g} / \mathrm{mL}$ and $400 \mu \mathrm{g} / \mathrm{mL}$ of DG or FG extracts for $8 \mathrm{~h}$. Soluble $A \beta 42$ level was measured from the supernatant of conditioned media using the sandwich ELISA method as described in the Materials and Methods. The data represent the mean \pm SEM $(n=3)$. "'Significantly different $(p<0.01)$ from the control group.

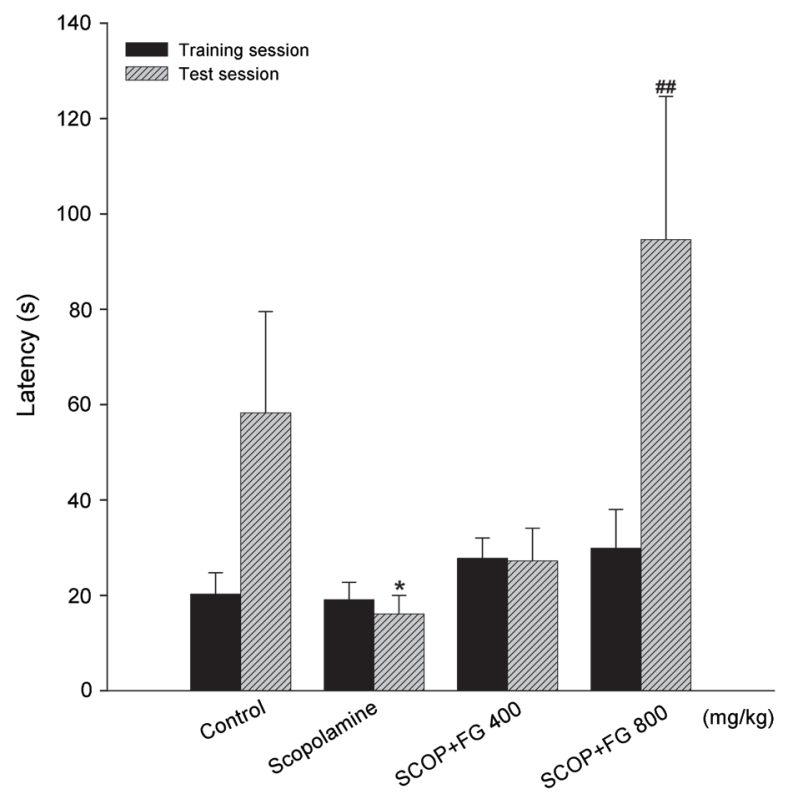

Fig. 3. Effect of fermented ginseng (FG) extract on step through passive avoidance test. FG extract (400 or $800 \mathrm{mg} / \mathrm{kg}$, per os, daily) was administered to 8 -weeks-old ICR mice for 2 wk and 30 min prior to intra peritoneal scopolamine injection $(1 \mathrm{mg} / \mathrm{kg}$ ). Then, the mice underwent the training session for the passive avoidance test $45 \mathrm{~min}$ after the scopolamine injection. After $24 \mathrm{~h}$, the test session was performed, and the latency to enter the dark compartment was recorded for up to $300 \mathrm{~s}$. The data represent the mean \pm SEM $(n=10)$. SCOP, scopolamine treated. "Significantly different $(p<0.05)$ from the control group. ${ }^{\#}$ Significantly different $(p<0.01)$ from the scopolamine control group. 


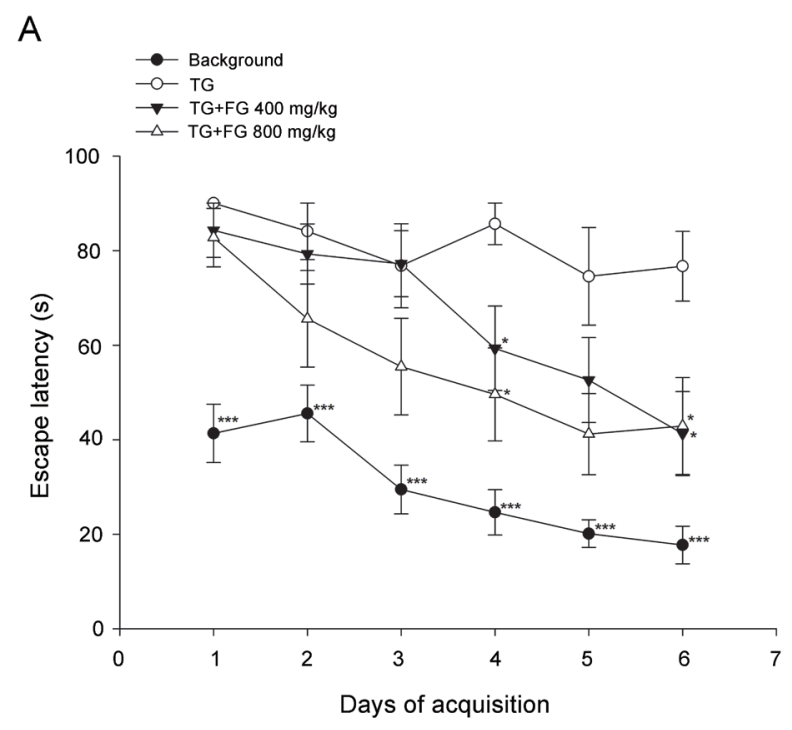

B

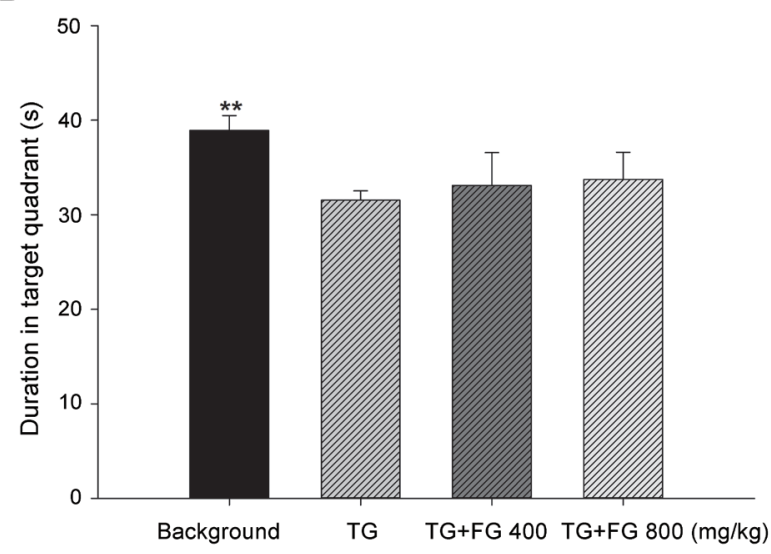

Fig. 4. Effect of fermented ginseng (FG) extract during the Morris water maze test. The FG extract (400 or $800 \mathrm{mg} / \mathrm{kg}$, daily) or saline was administered orally to 7-months-old transgenic (TG) mice for 4 $\mathrm{mo}$ and $1 \mathrm{~h}$ before the first trial of each acquisition day. The acquisition phase (A) consisted of 6 consecutive days in which each TG mouse accomplished total of 3 trials with a $2 \mathrm{~h}$ inter-trial interval. During the acquisition phase, the escape latency, the amount of time in seconds that it took the mouse to find the hidden platform was measured. The retention phase (B) occured the day immediately following the last day of the acquisition phase. During retention phase, the platform was removed, and the mice were allotted $120 \mathrm{~s}$ to explore the pool, and the duration of the time spent in the target quadrant, which had contained the escape platform during the acquisition phase, was measured. The data represent the mean \pm SEM $(n=7)$. " $p<0.05, " p<0.01, " p<0.001$ from the TG control group.

\section{Effect of fermented ginseng extract on perfor- mance of the Morris water maze test}

To assess spatial memory function, $6 \mathrm{~d}$ of acquisition phase was conducted with TG mice. As shown in Fig. 4A, non-TG background mouse group showed a significant increase of memory function from the 1st day $(41.36 \pm 6.19 \mathrm{~s})$ to the 6 th day $(17.75 \pm 3.98 \mathrm{~s})$ compared

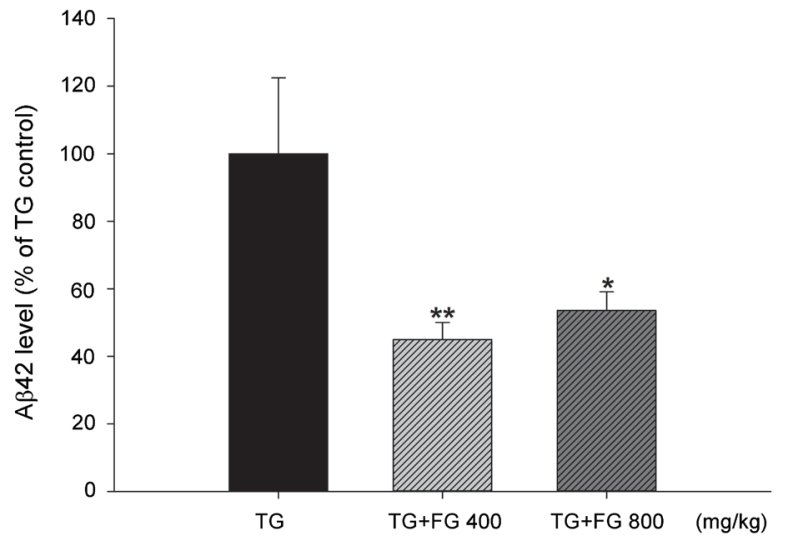

Fig. 5. Effect of fermented ginseng (FG) extract on the level of soluble $\beta$-amyloid $(A \beta) 42$ protein in the mouse cerebral cortex. Transgenic (TG) mouse brain tissue was collected after behavioral test at $11 \mathrm{mo}$ of age. The brain samples $(100 \mathrm{mg})$ were homogenized in Tris-buffered saline solution (20 mM Tris, $137 \mathrm{mM} \mathrm{NaCl}, \mathrm{pH} 7.4$ ) containing complete protease inhibitors tablets. The extraction ratio (brain tissue:Tris-buffered saline) was 1:5 or 1:10 (w/v). The tissue homogenates were centrifuged at $100,000 \mathrm{~g}$ for $1 \mathrm{~h}$ at $4^{\circ} \mathrm{C}$. Soluble $A \beta 42$ level in the resulting supernatants were measured using the sandwich ELISA kit according to the manufacturer's protocol. The data represent the mean \pm SEM $(n=7) . " p<0.05, " * p<0.01$ from the TG control group.

with the TG mouse group. In contrast, TG mice showed no progress in finding the escape platform from the 1st day $(90.06 \pm 0.00 \mathrm{~s})$ to the 6 th day $(76.69 \pm 7.39 \mathrm{~s}) . \mathrm{FG}$ extract treatments, 400 and $800 \mathrm{mg} / \mathrm{kg}$, exhibited significant dose-dependent enhancement of escape latency starting from $84.30 \pm 5.75$ and $82.76 \pm 6.19 \mathrm{~s}$ on the 1 st day to $41.30 \pm 8.90$ and $42.90 \pm 10.25 \mathrm{~s}$ on the 6 th day, respectively. Subsequently, spatial memory was tested on the 7th day during the retention phase. As shown in Fig. 4B, the duration in the target quadrant, which had contained the escape platform, significantly decreased in the TG mouse group $(31.53 \pm 0.99 \mathrm{~s})$ compared with the nonTG background mouse group (38.92 $\pm 1.56 \mathrm{~s}$ ). However, FG extract 400 and $800 \mathrm{mg} / \mathrm{kg}$ treated groups showed a tendency to increase the duration in target quadrant up to $33.10 \pm 3.47$ and $33.72 \pm 2.88 \mathrm{~s}$, respectively, compared with the untreated TG mouse group.

\section{Level of $\boldsymbol{\beta}$-amyloid $\mathbf{4 2}$ in fermented ginseng-treat- ed transgenic mice}

$A \beta 42$, a toxic form of $A \beta$ that increases in $A D$, increased dramatically in the cerebral cortex of TG mouse group compared with the non-TG background mice. However, FG extract 400 and $800 \mathrm{mg} / \mathrm{kg}$ treatment significantly reduced the level of $\mathrm{A} \beta 42$ down to $44.95 \pm 5.08 \%$ and $53.59 \pm 5.50 \%$, respectively (Fig. 5). 


\section{DISCUSSION}

$\mathrm{AD}$ is an age-related neurodegenerative disorder with progressive cognitive dysfunction and characterized by presence of senile plaques in the brain. $A \beta$ is the major component of senile plaques and is considered to have a causal role in the development and progress of AD [19]. Over the years, various research studies have reported, $P$. ginseng, especially ginsenosides such as $\mathrm{Rg} 1$ and $\mathrm{Rb} 1$, to exhibit neuroprotection against $\mathrm{AD}$ with respect to the A $\beta$-related symptoms [20-24]. However, other ginsenosides such as Rg3, Rg5, and Rk1 have not been widely studied in the area of neurodegenerative disease. The FG extract used in this study was compared with DG extract due to their different compositions of ginsenosides. We found that FG extract consists of less Re, Rg1, and $\mathrm{Rb} 1$ and more $\mathrm{Rg} 3, \mathrm{Rg} 5$, and Rk1 compared with the DG extract. Based on our pilot study, the comparison of various kinds of ginsenosides on the in vitro $\mathrm{A} \beta$ reduction effect resulted in $\mathrm{Rg} 3$ exhibiting a stronger effect compared with the same concentration of $\operatorname{Rg} 1$ (data not shown). The soluble A $\beta 42$ level that was measured in vitro also revealed that the $\mathrm{FG}$ extract was more effective at reducing $A \beta 42$ protein than the $D G$ extract. These results suggest that ginsenoside $\mathrm{Rg} 3, \mathrm{Rg} 5$, and $\mathrm{Rk} 1$, or the combination of these ginsenosides needs to be further investigated in AD-related models.

To confirm our hypothesis that the FG extract would be effective in animal models of $\mathrm{AD}$, we used two animal models that exhibit amnesia and $A \beta$ accumulation.

Through many previous studies, scopolamine treatment is a well-supported model of the learning and memory symptoms found with increasing age and dementia [2527]. Cholinergic deficits are neuropathological occurrences that are consistently associated with memory loss and are correlated with the severity of AD [28].

In the present study, we first attempted to examine the effect of FG extract on memory impairment induced by scopolamine injection using the step-through passive avoidance test; this test is a useful tool for the estimation of standard learning and memory function [29,30]. The result of this behavioral study indicates that FG extract has a significant ameliorating effect on the scopolamineinduced memory dysfunction, which indicates FG as a possible candidate as a symptomatic treatment for AD.

Although a symptomatic treatment can be effective in delaying the cognitive impairment in $\mathrm{AD}$ patients, it is not a fundamental treatment for the disease. Thus, further investigations on the causal mechanism for $\mathrm{AD}$, such as $\mathrm{A} \beta$ formation, are needed.
AD-related TG mice with APP and presenilin-1 mutation exhibit increased $A \beta$ formation and $A \beta$ plaques in the brain, which leads to severe cognitive malfunction $[31,32]$. We attempted to examine the effect of FG extract on TG mice to reveal the effect of prolonged treatment of $F G$ on $A \beta$ formation.

The MWM test, a well-known behavioral task used in various studies [33] to measure spatial memory, was also used in this study. Compared with TG control group, FG extract-treated groups showed consistent learning of the escape platform in the water maze. On the last day of the acquisition phase, the FG extract-treated groups showed a significantly decreased escape latency, which indicates an increased ability to remember the position of escape platform. On the 7th day of the experiment, the retention phase test was conducted. The non-TG background mouse group showed significantly increased swimming time in the target quadrant where the escape platform existed during the previous 6 experimental days. Compared with the non-TG background mouse group, TG control mice showed significantly decreased time spent in the target quadrant. The FG extract treatment, however, showed a tendency to increase the average time spent to find the escape platform compared with the TG control mouse group. In addition, during the probe phase, numbers of zone transition of the swimming mouse from other quadrant areas to target quadrant decreased to $74 \%$ compared to non-TG background mouse group. The FG extract treated groups recovered the zone transition rate up to $89 \%$ (data not shown).

Because of the spatial memory enhancing effect of FG in the TG mice, we assumed that the effect could be caused by an $A \beta$ reduction in the brain. Therefore the toxic $A \beta 42$ protein, which can induce formation of $A \beta$ plaques in the $\mathrm{AD}$ brain $[34,35]$, was measured in the brains of TG mice.

TG control mouse group exhibited significantly increased amount of $A \beta 42$ protein level in the cerebral cortex compared with the non-TG background mouse group. However, FG extract treatment significantly ameliorated the $A \beta 42$ protein level in the brains of the mice.

These results suggest that FG extract can ameliorate memory impairment, which is a symptom that can be found in $\mathrm{AD}$. Furthermore, restoration of cognitive function is partially due to the reduction of $\mathrm{A} \beta 42$ protein accumulation in the brain, which was due to the prolonged treatment of FG extract containing $\mathrm{Rg} 3, \mathrm{Rg} 5$, and Rk1, as well as $\mathrm{Rg} 1$ and $\mathrm{Rb} 1$.

Further research on the mechanisms of FG effects and clinical investigations in $\mathrm{AD}$ may lead to $\mathrm{FG}$ being a candidate for treatment of AD. 


\section{ACKNOWLEDGEMENTS}

This work was funded and supported by the Ministry of Knowledge Economy, Korea (project no. 2M25740), the Korea Institute of Science and Technology, Korea (project no. 2Z03550) and Well-being LS Co., Ltd., Korea.

\section{REFERENCES}

1. Chauhan NB, Sandoval J. Amelioration of early cognitive deficits by aged garlic extract in Alzheimer's transgenic mice. Phytother Res 2007;21:629-640.

2. Heo JH, Lee ST, Oh MJ, Park HJ, Shim JY, Chu K, Kim MH: Improvement of cognitive deficit in Alzheimer's disease patients by long term treatment with Korean red ginseng. J Ginseng Res 2011; 35:457-461.

3. Selkoe DJ. Toward a comprehensive theory for Alzheimer's disease. Hypothesis: Alzheimer's disease is caused by the cerebral accumulation and cytotoxicity of amyloid beta-protein. Ann N Y Acad Sci 2000;924:17-25.

4. Selkoe DJ. Cell biology of protein misfolding: the examples of Alzheimer's and Parkinson's diseases. Nat Cell Biol 2004;6:1054-1061.

5 . Yoon SS, Jo SA. Mechanisms of amyloid- $\beta$ peptide clearance: potential therapeutic targets for Alzheimer's disease. Biomol Ther (Seoul) 2012;20:245-255.

6. Yeo HB, Yoon HK, Lee HJ, Kang SG, Jung KY, Kim L: Effects of Korean red ginseng on cognitive and motor function: a double-blind, randomized, placebo-controlled trial. J Ginseng Res 2012; 36:190-197.

7. Jesky R, Hailong C. Are herbal compounds the next frontier for alleviating learning and memory impairments? An integrative look at memory, dementia and the promising therapeutics of traditional chinese medicines. Phytother Res 2011;25:1105-1118.

8. Zhao H, Li Q, Zhang Z, Pei X, Wang J, Li Y. Long-term ginsenoside consumption prevents memory loss in aged SAMP8 mice by decreasing oxidative stress and upregulating the plasticity-related proteins in hippocampus. Brain Res 2009;1256:111-122.

9. Tohda C, Matsumoto N, Zou K, Meselhy MR, Komatsu K. Abeta(25-35)-induced memory impairment, axonal atrophy, and synaptic loss are ameliorated by M1, A metabolite of protopanaxadiol-type saponins. Neuropsychopharmacology 2004;29:860-868.

10. Sano M, Grossman H, Van Dyk K. Preventing Alzheimer's disease: separating fact from fiction. CNS Drugs 2008;22:887-902.

11. Attele AS, Wu JA, Yuan CS. Ginseng pharmacology: multiple constituents and multiple actions. Biochem Phar- macol 1999;58:1685-1693.

12. Trinh HT, Han SJ, Kim SW, Lee YC, Kim DH. Bifidus fermentation increases hypolipidemic and hypoglycemic effects of red ginseng. J Microbiol Biotechnol 2007; 17:1127-1133.

13. Jeon WJ, Oh JS, Park MS, Ji GE. Anti-hyperglycemic effect of fermented ginseng in type 2 diabetes mellitus mouse model. Phytother Res 2012; Epub ahead of print.

14. Park JW, Lee JC, Ann S, Seo DW, Choi WS, Yoo YH, Park SK, Choi JY, Um SH, Ahn SH et al. A fermented ginseng extract, BST204, inhibits proliferation and motility of human colon cancer cells. Biomol Ther (Seoul) 2011;19:211-217.

15. Yuan HD, Chung SH. Fermented ginseng protects streptozotocin-induced damage in rat pancreas by inhibiting nuclear factor-kappaB. Phytother Res 2010;24 Suppl 2:S190-S195.

16. Seo JY, Lee JH, Kim NW, Her E, Chang SH, Ko NY, Yoo YH, Kim JW, Seo DW, Han JW et al. Effect of a fermented ginseng extract, BST204, on the expression of cyclooxygenase- 2 in murine macrophages. Int Immunopharmacol 2005;5:929-936.

17. Jung JW, Kang HR, Ji GE, Park MS, Song WJ, Kim MH, Kwon JW, Kim TW, Park HW, Cho SH et al. Therapeutic effects of fermented red ginseng in allergic rhinitis: a randomized, double-blind, placebo-controlled study. Allergy Asthma Immunol Res 2011;3:103-110.

18. Landman N, Jeong SY, Shin SY, Voronov SV, Serban G, Kang MS, Park MK, Di Paolo G, Chung S, Kim TW. Presenilin mutations linked to familial Alzheimer's disease cause an imbalance in phosphatidylinositol 4,5-bisphosphate metabolism. Proc Natl Acad Sci U S A 2006;103:19524-19529.

19. Alkam T, Nitta A, Mizoguchi H, Itoh A, Nabeshima T. A natural scavenger of peroxynitrites, rosmarinic acid, protects against impairment of memory induced by Abeta(25-35). Behav Brain Res 2007;180:139-145.

20. Fang F, Chen X, Huang T, Lue LF, Luddy JS, Yan SS. Multi-faced neuroprotective effects of Ginsenoside Rg1 in an Alzheimer mouse model. Biochim Biophys Acta 2012;1822:286-292.

21. Shi YQ, Huang TW, Chen LM, Pan XD, Zhang J, Zhu YG, Chen XC. Ginsenoside Rg1 attenuates amyloid-beta content, regulates PKA/CREB activity, and improves cognitive performance in SAMP8 mice. J Alzheimers Dis 2010;19:977-989.

22. Wang YH, Du GH. Ginsenoside Rg1 inhibits betasecretase activity in vitro and protects against Abetainduced cytotoxicity in PC12 cells. J Asian Nat Prod Res 2009;11:604-612. 
23. Zhao R, Zhang Z, Song Y, Wang D, Qi J, Wen S. Implication of phosphatidylinositol-3 kinase/Akt/glycogen synthase kinase- $3 \beta$ pathway in ginsenoside Rb1's attenuation of beta-amyloid-induced neurotoxicity and tau phosphorylation. J Ethnopharmacol 2011;133:1109-1116.

24. Wang Y, Liu J, Zhang Z, Bi P, Qi Z, Zhang C. Anti-neuroinflammation effect of ginsenoside $\mathrm{Rbl}$ in a rat model of Alzheimer disease. Neurosci Lett 2011;487:70-72.

25. Araujo JA, Studzinski CM, Milgram NW. Further evidence for the cholinergic hypothesis of aging and dementia from the canine model of aging. Prog Neuropsychopharmacol Biol Psychiatry 2005;29:411-422.

26. Fischer W, Chen KS, Gage FH, Bjorklund A. Progressive decline in spatial learning and integrity of forebrain cholinergic neurons in rats during aging. Neurobiol Aging 1992;13:9-23.

27. Tariot PN, Patel SV, Cox C, Henderson RE. Age-related decline in central cholinergic function demonstrated with scopolamine. Psychopharmacology (Berl) 1996;125:5056.

28. Giacobini E. The cholinergic system in Alzheimer dis- ease. Prog Brain Res 1990;84:321-332.

29. Bejar C, Wang RH, Weinstock M. Effect of rivastigmine on scopolamine-induced memory impairment in rats. Eur J Pharmacol 1999;383:231-240.

30. Fibiger HC. Cholinergic mechanisms in learning, memory and dementia: a review of recent evidence. Trends Neurosci 1991;14:220-223.

31. Epis R, Gardoni F, Marcello E, Genazzani A, Canonico PL, Di Luca M. Searching for new animal models of Alzheimer's disease. Eur J Pharmacol 2010;626:57-63.

32. Woodruff-Pak DS. Animal models of Alzheimer's disease: therapeutic implications. J Alzheimers Dis 2008;15:507521.

33. Sharma S, Rakoczy S, Brown-Borg H. Assessment of spatial memory in mice. Life Sci 2010;87:521-536.

34. Galimberti D, Scarpini E. Alzheimer's disease: from pathogenesis to disease-modifying approaches. CNS Neurol Disord Drug Targets 2011;10:163-174.

35. Evin G, Barakat A, Masters CL. BACE: therapeutic target and potential biomarker for Alzheimer's disease. Int J Biochem Cell Biol 2010;42:1923-1926. 